\title{
Pós-parto e sexualidade: perspectivas e ajustes maternos
}

Postpartum and sexuality: maternal perspectives and adjustments

Posparto y sexualidad: perspectivas y ajustes maternos

\section{Larissa Karla Rocha Siqueira', Mônica Cecília Pimentel de Melo" Ramon José Leal de Morais ${ }^{\text {III }}$}

\begin{abstract}
Resumo: Objetivo: analisar as perspectivas e adaptações maternas da sexualidade no puerpério e identificar se houveram orientações no pré-natal. Método: qualitativo, exploratório e descritivo, no Hospital Dom Malan, em Petrolina - Pernambuco, com 12 puérperas entrevistadas, segundo análise temática de conteúdo. Resultados: o medo da dor foi a principal expectativa, além do receio de uma nova gravidez, preocupações com os cuidados com o bebê e insegurança com o próprio corpo. O diálogo com o companheiro mostrou-se importante para a manutenção da relação. As mulheres declararam que não houve orientações no pré-natal. Conclusão: após o nascimento do bebê o casal precisa fazer muitos ajustes para gradualmente retomar sua intimidade. Nesse contexto o enfermeiro tem papel fundamental, pois possui conhecimento para oferecer informações necessárias em relação ao puerpério, favorecendo uma experiência materna de retorno à sexualidade saudável e prazerosa.
\end{abstract}

Descritores: Sexualidade; Poder familiar; Período Pós-Parto; Saúde da mulher

\begin{abstract}
Aim: to analyze the perspectives and maternal adaptations of sexuality in the puerperium and to identify if there were guidelines in prenatal care. Method: qualitative, exploratory and descriptive, at the Hospital Dom Malan, in Petrolina - Pernambuco, with 12 postpartum women interviewed, according to content thematic analysis. Results: Fear of pain was the main expectation, besides the fear of a new pregnancy, concerns about the care of the baby and insecurity with the body itself. The dialogue with the partner was important for the maintenance of the relationship. The women stated that there were no prenatal guidelines. Conclusion: After the baby's birth, the couple needs to make many adjustments to gradually regain their intimacy. In this context, the
\end{abstract}

\footnotetext{
I Enfermeira. Pós graduanda pelo Programa de Residência em Enfermagem Obstétrica do Hospital IMIP/Dom Malan. Petrolina, Pernambuco, Brasil. Email: 1kr.siqueira@gmail.com Orcid: https://orcid.org/0000-0002-5013-2402

II Enfermeira. Doutora em Educação em Ciências, Química da Vida e Saúde UFRGS/UFSM/FURG. Docente em Enfermagem da Universidade Federal do Vale do São Francisco (UNIVASF). Petrolina, Pernambuco, Brasil. Email: monquinamelo@gmail.com Orcid: http://orcid.org/0000-0003-4029-4886

III Enfermeiro. Mestre em Educação para o Ensino na Área da Saúde pela Faculdade Pernambucana de Saúde - FPS. Docente em Enfermagem da Universidade Federal do Vale do São Francisco (UNIVASF). Petrolina, Pernambuco, Brasil. Email: ramonmorais_dm@hotmail.com Orcid: http://orcid.org/0000-0002-2099-6074
} 
nurse has a fundamental role, since he/she has the knowledge to offer necessary information regarding the puerperium, favoring a healthy and pleasurable maternal experience of return to sexuality.

Descriptors: Sexuality; Family power; Postpartum period; Women's health

Resumen: Objetivo: analizar las perspectivas y adaptaciones maternas de la sexualidad en el puerperio e identificar si hubo orientaciones en la atención prenatal. Método: cualitativo, exploratorio y descriptivo, en el Hospital Dom Malan, en Petrolina - Pernambuco, con 12 mujeres entrevistadas en el postparto, a partir del análisis temático de contenido. Resultados: el temor al dolor era la principal expectativa, además del temor a un nuevo embarazo, de las preocupaciones sobre el cuidado del bebé y de la inseguridad con el propio cuerpo. El diálogo con la pareja fue importante para el mantenimiento de la relación. Las mujeres afirmaron que no hubo orientaciones en la atención prenatal. Conclusión: después del nacimiento del bebé, la pareja debe hacer muchos ajustes para recuperar gradualmente su intimidad. En ese contexto, la enfermera desarrolla un papel fundamental, ya que tiene el conocimiento para ofrecer la información necesaria sobre el puerperio, favoreciendo una experiencia materna de regreso a una sexualidad saludable y placentera.

Descriptores: sexualidad; Poder de la familia; Período posparto; Salud de la mujer

\section{Introdução}

Segundo o Ministério da Saúde (MS) a ideia acerca dos direitos sexuais resulta, em especial, na aceitação de diferentes tipos de expressão sexual, autonomia para tomar decisões sobre o uso do corpo e igualdade de gênero. ${ }^{1}$ Essas questões fundamentam a liberdade de expressão e estimula uma cultura, na qual, a sexualidade feminina é valorizada e motiva um maior posicionamento de suas ações perante toda sua vida social. ${ }^{2}$

Considerada como fenômeno complexo, a sexualidade feminina possui determinantes variados, podendo a relação sexual ser motivada por diversos fatores: psicológicos, socioculturais e relacionais. Ao longo de sua vida sexual, a mulher vivencia uma série de adaptações físicas e emocionais. Neste sentido, o puerpério merece um olhar mais atento, visto que acarreta importantes modificações na vida da mulher, do parceiro e da família. ${ }^{3}$

O puerpério tem início após a saída da placenta estendendo-se até 6 semanas completas após o parto. Essa definição é baseada nas modificações locais e sistêmicas, causadas pela gestação no organismo materno, que, ao final desse período, já retornaram ao estado pré- 
gravídico. ${ }^{4}$ No entanto, muitos estudos assumem como pós-parto remoto o período além do $45^{\circ}$ dia até 12 meses que sucedem o parto, visto que além da relevância desses mecanismos fisiológicos para o restabelecimento do estado pré-gravídico da mulher, o puerpério é também caracterizado por marcantes mudanças em diversos outros aspectos da vida feminina, sejam eles conjugais, familiares, sociais ou profissionais. ${ }^{5}$

No estágio em questão, o déficit de estrogênio e progesterona, associado ao aumento de prolactina, causam redução do desejo sexual e da lubrificação vaginal, o que justifica a insatisfação de mulheres em relação à resposta sexual. O assoalho perineal é responsável pela função que permite o intercurso sexual e o parto, entretanto, as lacerações internas resultantes da passagem do feto, podem provocar dificuldades em obter prazer sexual. Além disso, o estrogênio também é responsável pela elasticidade e viscosidade da pele e mucosa vaginal, e, portanto, sua redução leva à dispareunia, e consequentemente, à diminuição da libido em longo prazo. $^{6}$

O percurso sexual do pós-parto não ocorre somente no âmbito fisiológico, endócrino e genital, mas na sua totalidade enquanto pessoa. O puerpério é um período de conflitos em que se alternam na mulher sentimentos de alegria, medo, alívio, ansiedade, realização, dúvida, entre outros. É bem comum que muitas mulheres sintam receios relacionados ao período puerperal, uma vez que, muitas delas, ainda não se sentem preparadas para encarar os desafios de ser mãe. ${ }^{7}$

Nesse período a vivência da sexualidade é muito complexa, e associa-se, geralmente, a diminuição do bem-estar biológico, psicológico, conjugal e familiar, implicando, muitas vezes, em uma reestruturação na vida do casal. A desmotivação da mulher para a relação sexual está relacionada às mudanças fisiológicas, psicológicas, sociais e emocionais; ao cuidado com o recém-nascido; à crença por parte do casal no mito da ocorrência de danos irreparáveis no aparelho genital feminino; e, ainda, o parceiro não percebendo o desejo na mulher, sente-se 
desconfortável com os seus desejos e gera na mulher a sensação de não ser mais atraente e desejável. ${ }^{8}$

Portanto, a realidade da maternidade e da paternidade configura em transformações significativas na vida familiar, especialmente, no que se refere ao retorno da sexualidade nesse período. Outrossim, a mudança para o papel de nutriz e cuidadora de uma criança tem sido uma das maiores dificuldades encontradas pelas mulheres no período pós-parto, devido às questões sociais, culturais e estéticas. ${ }^{9}$

A amamentação pode acarretar sensações e sentimentos distintos para as mulheres quando relacionada à sexualidade, pois possui aspectos socioculturais com diferentes sentidos e aspectos na vida de cada mulher. Durante o puerpério, as expectativas estão voltadas para o cuidado do bebê, subestimando sentimentos, desejos, condições físicas e emocionais da mãe/nutriz. ${ }^{10}$

Nesse contexto, o puerpério é um dos momentos mais marcantes para a mulher e sua família, principalmente, no que diz respeito à interação sexual com o parceiro diante dessa nova realidade, pois a chegada de um bebê requer uma nova rotina familiar. Entretanto, nem sempre as mulheres que estão cercadas de expectativas vivenciam esse período de forma semelhante, pois estão imersas em contextos, mudanças e desafios distintos.

Diante disso, a relevância do estudo está pautada na possibilidade de compreensão e análise das perspectivas e ajustes maternos quanto à sexualidade no período puerperal, emergindo, a partir daí, vivências diversas com implicações e adaptabilidades diferentes para cada mulher/mãe sertaneja. Além disso, querer-se-á ressaltar o papel de destaque do pré-natal, devido ao esclarecimento para a gestante sobre as mudanças fisiológicas e sociais que irão ocorrer no período pós-parto.

Por conseguinte, buscando compreender as principais expectativas e adaptações no período pós-parto no que se refere à sexualidade, em um lócus diferenciado - sertão 
pernambucano - surge como questão de pesquisa: Quais as perspectivas e ajustes maternos relativos à sexualidade no pós-parto? Logo, se pretendeu analisar as perspectivas e adaptações maternas da sexualidade no puerpério e identificar se houveram orientações no pré-natal.

\section{Método}

Trata-se de uma pesquisa qualitativa, exploratória e descritiva, realizada em um hospital maternidade de nível terciário que atende exclusivamente usuários do Sistema Único de Saúde (SUS). É o único centro de referência para alta complexidade obstétrica e neonatal na Região Integrada do Desenvolvimento (RIDE) do Pólo Petrolina - Pernambuco (PE) e Juazeiro - Bahia (BA).

Fizeram parte da pesquisa 12 puérperas internadas no alojamento conjunto do hospital, no período de setembro a outubro de 2017, as quais foram selecionadas por amostra não probabilística, do tipo intencional, com fechamento por saturação teórica. O critério de inclusão foi estar em condições físicas e psicológicas de responder aos questionamentos, avaliadas pela pesquisadora responsável, e os critérios de exclusão foram estarem no pós-parto imediato de cesariana e/ou possuírem diagnóstico de distúrbio psicológico. Por se tratar de um tema de cunho muito íntimo, observou-se que, em média, a cada 4 ou 5 puérperas que se enquadravam nos critérios de inclusão e eram convidadas a colaborar, apenas 1 aceitava participar da pesquisa.

A fim de garantir sigilo e privacidade nas entrevistas, as mulheres que aceitaram participar foram conduzidas individualmente ao consultório do alojamento conjunto. Realizouse a entrevista semiestruturada, contendo dados para caracterização sociodemográfica e obstétrica, além de questões abertas acerca das perspectivas e ajustes maternos relativos à sexualidade no pós-parto. As puérperas foram abordadas com as seguintes questões: "Conte-me quais são suas expectativas acerca do retorno à atividade sexual após o parto; Fale-me sobre os 
sentimentos e os significados que você atribui a este momento; Na sua opinião, quais as maiores dificuldades no que tange à sexualidade no puerpério? Como você gostaria que fosse o retorno à sexualidade com seu parceiro nesse período? Que orientações houve durante o pré-natal quanto ao período puerperal e o retorno a atividade sexual após o parto?” As entrevistas foram gravadas e tiveram duração média de 20 minutos.

Para análise e interpretação dos resultados foi utilizada a técnica de Análise Temática de Conteúdo. Este tipo de análise tem por objetivo a descrição do conteúdo da mensagem e a categorização conforme os temas quem emergem do texto. ${ }^{11}$ As participantes foram identificadas pela inicial “E” (entrevista) e enumeradas conforme a ordem da aplicação do instrumento.

Todas as entrevistadas assinaram o Termo de Consentimento Livre e Esclarecido em duas vias, e receberam uma cópia do mesmo. A pesquisa foi aprovada pelo Comitê de Ética e Pesquisas da Universidade Federal do Vale do São Francisco, sob o parecer nº 1.896 .604 em 23 de janeiro de 2017.

\section{Resultados e discussão}

Foram entrevistadas 12 puérperas, com idades entre 18 e 29 anos, na qual, 10 declararam união estável com o companheiro e duas eram casadas. Quanto ao grau de escolaridade, quatro possuíam o ensino fundamental incompleto, duas o ensino médio incompleto, quatro o ensino médio completo e duas o ensino superior incompleto. Seis puérperas eram primíparas, 9 tiveram parto cesáreo e 10 alegaram ter tido alguma intercorrência na gestação, este último dado justifica-se por tratar de um hospital de referência para gestação de alto risco.

Durante a análise, o conteúdo das entrevistas foi agrupado em categorias temáticas, segundo a similaridade em relação aos assuntos abordados.

Expectativas acerca do retorno à atividade sexual 
Esta categoria aborda as principais expectativas acerca do retorno à atividade sexual com o companheiro. Os relatos demonstraram que o medo de sentir dor foi frequentemente associado à relação sexual após o parto.

Voltar a ter relação me deixa um pouco apreensiva, principalmente, por causa da dor, porque vai doer?! (E3)

[...] eu fico meio nervosa, porque para mim eu acho que vai doer [...]. (E7)

[...] acho que as dores é como se fosse uma primeira vez novamente, você fica um pouquinho travada, pensando, ah vai doer [...]. (E9)

Tal sentimento foi manifestado por oito das 12 puérperas entrevistadas, não havendo distinção entre as respostas e a via de parto (cesáreo ou parto vaginal).

Assim, eu fico imaginando de sentir dor, porque o corpo está se recuperando do parto normal, né?!(E1)

[...] sobre pós-parto cesáreo eu não tenho nenhuma experiência então tenho medo de doer, devido a cirurgia, vou buscar informação entendeu?! (E10)

O medo de sentir dor foi destacado no relato das puérperas, posto que a dispareunia é um dos aspectos de maior incidência na retomada das atividades sexuais no pós-parto. Independente da via de parto, os baixos níveis de estrogênio nesse período tendem a reduzir a lubrificação e a elasticidade vaginal, causando dor e desconforto durante a penetração, o que justifica, para maioria das mulheres, o puerpério como um período de reduzida ou ausente atividade sexual, principalmente, com relação ao coito. Além disso, há também a preocupação com o período de tempo necessário para o aparelho genital recuperar-se do parto, particularmente na ocorrência de episiotomia ou laceração. A dor, no momento da relação sexual, influencia negativamente a vivência da sexualidade feminina, tanto no 
comprometimento da saúde sexual como na prática da relação, gerando insatisfação nas mulheres. ${ }^{6,12}$

Estudo de revisão afirma que não há um consenso na literatura a respeito da correlação entre a via de parto e a disfunção sexual feminina. A dispareunia nos três primeiros meses foi associada significativamente com partos vaginais, mas o percentual diminui após seis meses pós-parto, com melhora significativa da função sexual. A cesariana eletiva não parece ser vantajosa em comparação com o parto vaginal quanto à função sexual de 6-24 semanas pósparto, pois a mulher volta a atividade sexual normalmente, independente da via de parto. ${ }^{13}$

Contudo, a relação sexual no período pós-parto pode ser bastante dolorosa e muito incômoda, portanto, capaz de gerar conflito com o parceiro, desgaste do relacionamento e afastamento do casal. Nesse momento, as carícias e preliminares podem estimular uma maior lubrificação vaginal, além disso, o uso de lubrificantes artificiais também ajuda a minimizar a sensação dolorosa durante a penetração.

Outro receio manifestado pelas mulheres foi o medo de uma nova gravidez durante o período puerperal. De acordo com os depoimentos das mulheres, a possibilidade de uma gestação precoce influencia negativamente a retomada sexual, como observado nestas falas:

Mulher, [...] se preparar, para não vir outra gravidez, eu já estava me perguntando: qual será o remédio que eu vou tomar?!(E3)

[...] vai demorar um bocado, porque a gente não deve pensar nessas coisas, a gente tem que pensar no bem-estar, se prevenir contra uma gravidez precoce, eu acho que deixar passar o resguardo, depois passar mais uns dias, aí quando começar a tomar a medicação correta, aí sim, pensar em fazer. (E5)

O medo de uma nova gravidez foi determinante para a maioria das puérperas entrevistadas, demonstrando que o conhecimento e as informações relacionados a esse assunto são insuficientes ou precárias, o que pode ocasionar, por vezes, na mulher ou no casal, 
sentimentos de dúvida, insegurança e o medo de uma nova gestação. Para tanto, o ideal é que haja esclarecimento sobre o planejamento familiar no pós-parto, de preferência, ainda durante o pré-natal, pois a aceitação do método, a credibilidade em sua eficácia, a motivação para usá-lo e a correta orientação do profissional de saúde são fatores determinantes para o sucesso do método escolhido. ${ }^{12}$

Estudo reforça que a escolha do método contraceptivo deve ser sempre individualizado e discutido desde o pré-natal. Ao orientar o uso de métodos anticoncepcionais no período puerperal é recomendado considerar algumas questões como o tempo pós-parto, o retorno ou não da menstruação, o padrão da amamentação e as possíveis implicações hormonais sobre a lactação e o lactente. ${ }^{1}$

Portanto, para evitar uma nova gravidez no pós-parto é necessário que a puérpera conheça os métodos contraceptivos adequados e sinta-se segura para adotar a opção que lhe for mais conveniente. Em contrapartida, a assistência ao planejamento familiar, atualmente, realizada pelas Unidades de Saúde da Família, necessita superar algumas deficiências, principalmente, no que concerne ao fornecimento irregular e insatisfatório dos métodos, o que acarreta em menos opções de escolha para a mulher.

Além disso, de acordo com alguns depoimentos as puérperas sentem-se inseguras em relação às modificações físicas que ocorrem no ciclo gravídico-puerperal. Para estas mulheres tais mudanças implicam em evolução negativa da imagem corporal.

[...] você está insegura com o corpo porque ainda está voltando ao normal [...]. (E7)

[...] vai ter sempre uma insegurança, porque o corpo não vai ser do mesmo jeito. (E8)

As alterações corporais, sejam elas físicas e/ou hormonais, que acontecem ao longo do ciclo gravídico-puerperal associam-se, por vezes, ao sentimento de perda da autoestima devido a 
percepções subjetivas de pouca atratividade física e incapacidade de sedução. Comumente a adaptação biológica ocorre por volta de 6-8 semanas após o parto, no entanto, o retorno à imagem corporal prévia à gestação dificilmente acontece durante esse período, resultando, muitas vezes, na evolução negativa da autoimagem e da relação conjugal do casal. ${ }^{12-15}$

Segundo autores a autopercepção sobre o corpo no pós-parto está associada à forma que a puérpera compreende as mudanças corporais ocorridas, diante da subjetividade, relacionamentos e cultura de cada mulher. A sexualidade está intrinsicamente envolvida em toda essa nova realidade que a mulher vivencia, seja relacionada consigo, com seu corpo e sua feminilidade, ou com o contato e comunicação junto ao parceiro. ${ }^{16}$

Então, as percepções que as mulheres possuem sobre seus corpos no pós-parto estão ligadas à imagem corporal antes da gestação, pois se sentem incomodadas com o corpo atual, afetando a autoestima, a autoimagem, a sexualidade e o relacionamento com o parceiro.

Os depoimentos a seguir demonstram que para as puérperas a sexualidade no pós-parto está condicionada a mulher sentir-se confortável consigo e estar disposta a reiniciar sua vida sexual com o parceiro.

[...] que seja confortável para mim, para que seja bom tanto para mim, quanto para ele. (E1)

[...] entender, que a gente está num período que está se readaptando, tem que ser no momento certo. (E4)

A maioria das puérperas custa a sentir desejo sexual pelo parceiro, pois necessitam de tempo para se reconectarem com seu corpo e seus sentimentos. Portanto, pode-se dizer que, além das informações transmitidas pelos meios de comunicação e por profissionais, está a subjetividade de cada mulher e o autoconhecimento acerca do próprio corpo. Elas podem não ter conhecimentos científicos sobre a involução uterina ou fenômenos endócrinos ocorridos no período puerperal. Contudo, pôde-se constatar que para elas o mais importante é o bem-estar 
físico, psicológico e o respeito com o tempo do próprio corpo. Esse é um saber empírico sobre si e determinante para o retorno delas à vida sexual após o parto. ${ }^{16}$

Dessa maneira, a vivência da sexualidade no pós-parto deve ser baseada não apenas na recuperação fisiológica do corpo, mas, sobretudo, no restabelecimento emocional, diferente para cada mulher.

\section{Estratégias e ajustes do casal para a vivência da sexualidade no pós-parto}

Nesta categoria a rotina de cuidados com o bebê foi declarado pelas entrevistadas como revés ao retorno da intimidade sexual. $\mathrm{Na}$ fala de algumas mulheres pôde-se ver que a prioridade são as demandas maternas para depois pensar na relação com o parceiro, conforme revelado a seguir:

[...] agora com um bebê você vai ficar com o filho e tem menos tempo de ficar com o marido. (E4)

[...] é muito cansativo, você cuida da criança, na maioria das vezes você nem está com disposição para ter relação com o marido. (E5)

[...] a amamentação, a rotina com o nenén, é tipo um obstáculo no meio do casal. (E7)

No pós-parto, o casal geralmente concentra sua afetividade e atenção na criança recém chegada, o que por vezes, resulta em conflitos e tensões conjugais. Assim como visto no relato das puérperas, autores afirmam que o papel materno interfere na sexualidade do casal, pois a rotina de cuidados com o bebê exige tempo e dedicação para atender as necessidades e estabelecer o vínculo que será fundamental para o desenvolvimento do recém-nascido. ${ }^{14}$ Em outro estudo concluiu-se que as preocupações sexuais pós-parto são profundas e moderadamente angustiantes em novos pais, e que o aumento da frequência e gravidade dessas preocupações foi associado à diminuição do bem-estar do relacionamento em ambos os membros do casal. ${ }^{15}$ 
Nesse tocante, com as atenções voltadas para o bebê, o desafio é conciliar os papéis e se adaptar a essa nova rotina cheia de demandas. O tempo para se dedicar ao relacionamento, seja no âmbito sexual ou afetivo, será menor, mas também necessita de cuidados e carinho.

Diante dos ajustes que se fazem necessários para o bom relacionamento sexual do casal no período pós-parto, as puérperas declararam que o diálogo com o companheiro é importante para a manutenção da relação.

[...] um procurar o outro e conversar sobre isso. (E3)

A gente tem que sentar e conversar, estipular um determinado tempo para a relação sexual voltar à tona [...]. (E5)

[...] com o passar dos dias, a gente tem que conversar sobre isso. (E6)

O nascimento de um filho exige uma reorganização na rotina da família e adaptação do casal a uma nova realidade. É um momento em que a mulher está sensível e mais vulnerável a instabilidade emocional, assim, é fundamental que haja compreensão e apoio no contexto familiar. A participação do companheiro nesse período merece destaque, posto que ele vivencia sensações psicológicas semelhantes às da mulher. Por sua vez, o direcionamento dos acontecimentos pode repercutir de modo favorável ou não no relacionamento do casal. ${ }^{6}$

As diversas modificações que ocorrem no período puerperal comumente atingem a relação afetiva e sexual do casal e podem comprometer o equilíbrio familiar e/ou agravar dificuldades. O diálogo e a compreensão entre o casal se mostram de grande importância para ajudar a superar as enormes mudanças que o nascimento de um filho traz. Assim, o espaço exclusivo de relacionamento afetivo-sexual do casal é, igualmente, uma importante necessidade a ser valorizada no pós-parto. ${ }^{14-15}$ 
Desse modo, é importante que haja muito diálogo, compreensão e tolerância para compreenderem que estão passando por uma fase de rearranjos e experiências que, se bem administradas, servirão para uma maior aproximação do casal, harmonia e cumplicidade.

Também foi declarado pelas puérperas que além do papel de pais é necessário que o casal volte a se perceber como marido e mulher na relação familiar. Algumas entrevistadas sinalizaram essa necessidade:

[...] voltar a se enxergar como mulher, demonstrar carinho com o companheiro. (E2)

[...] voltar o vínculo do casal, se ver como marido e mulher novamente, porque nos primeiros dias a gente dá uma afastada. (E7)

Um estudo revela que além dos receios relacionados à recuperação física, as tarefas parentais e a preocupação com a maternidade se apresentam como obstáculos à sexualidade satisfatória, pois o marido e a mulher olham menos um para o outro e mais para o bebê, por ser o centro das atenções, fazendo com que o valor do casal não seja reconhecido e sintam-se rejeitados. ${ }^{12}$

Neste contexto as puérperas salientaram a necessidade da retomada do relacionamento e intimidade do casal, para isso é fundamental a disponibilidade para compreender e se reaproximar do parceiro, reservar um tempo a dois, demandar mais atenção ao companheiro e demostrar carinho, pois favorecem o restabelecimento do casal e facilitam o retorno à intimidade sexual.

\section{Informações recebidas no pré-natal acerca da sexualidade no pós-parto}

Por fim, quando questionadas sobre as orientações oferecidas durante o pré-natal, relativas à sexualidade no pós-parto, a maioria das mulheres declarou não ter recebido informações dos profissionais. 
Não houve, assim eu sei porque na nossa família a gente sempre fica falando. (E1)

Não, assim se eu não tivesse ligada, tinha que tomar remédio, usar camisinha, mas não foi falado nada disso durante o pré-natal. (E2)

Não, sobre o pós-parto não houve nenhuma orientação [...] eu gosto de está informada, então, eu pesquisei na internet. (E5)

Não, durante o pré-natal não, mas minha mãe já me orientou. (E8)

Apenas uma das entrevistadas manifestou ter recebido alguma orientação no pré-natal.

Tivemos, tivemos acompanhamento sobre o retorno, sobre os métodos contraceptivos, tivemos tudo isso no pré-natal, tudo diferente, muito atenciosa a enfermeira, o médico, tudo bem explicadinho, maravilhoso, teve palestras, muita coisa diferente. (E9)

A assistência integral à saúde feminina inclui estar atento a questões relacionadas à saúde sexual nos diferentes ciclos da vida reprodutiva da mulher, e exige do profissional de saúde, sobremaneira do (a) enfermeiro (a), conhecimento acerca dos processos fisiológicos e comportamentais que acometem mulheres no ciclo gravídico-puerperal, possibilitando a articulação de estratégias para o enfrentamento dessa realidade. ${ }^{17}$

Estudo realizado com 200 puérperas afirma que a maioria (83\%) das mulheres vivencia problemas sexuais nos três primeiros meses pós-parto. Nesse sentido o desempenho sexual durante a gravidez e após o parto é uma preocupação que envolve não somente a mulher, mas o casal, reforçando a necessidade de acolhimento e esclarecimentos pelos profissionais de saúde acerca das modificações da função e do interesse sexual ocorridos no puerpério. ${ }^{17}$

Entende-se, portanto, que as orientações sobre o retorno à sexualidade, contracepção pós-parto e planejamento familiar não podem ocorrer apenas na consulta puerperal. Sendo que tais esclarecimentos são fundamentais na assistência pré-natal por aumentarem a possibilidade 
de utilização correta do método contraceptivo e permitirem uma experiência positiva diante das dificuldades enfrentadas no puerpério pelos casais.

\section{Conclusão}

Por meio deste estudo pôde-se constatar que dentre as perspectivas das mulheres acerca da sexualidade no pós-parto, destaca-se o medo da dor durante a relação, não sendo influenciado pelo tipo de parto, concordando com outros estudos encontrados na literatura. O medo de uma nova gravidez também foi relatado pelas puérperas, reafirmando a importância do aconselhamento em relação à contracepção pós-parto ainda durante o pré-natal.

É fato que as mudanças orgânicas no período puerperal interferem sobremaneira no comportamento sexual da mulher, no entanto, em meio às entrevistas observou-se que as percepções das mulheres sobre seus corpos estão ligadas à ideologia do corpo biológico, afetando a auto percepção e influenciando negativamente a sua sexualidade e relacionamento com o parceiro. Além disso, os cuidados com o recém-nascido tornam-se prioritários na rotina familiar e de acordo com as puérperas dificultam a vivência sexual do casal no pós-parto.

Após o nascimento do bebê o casal precisa fazer muitos ajustes para gradualmente retomar sua intimidade. Reservar um tempo para ficarem a sós, compartilhar seus sentimentos, desejos, receios e necessidades possibilitam a reestruturação do relacionamento, garantindo o lugar da relação, além de tempo e espaço para cultivá-la.

Nesse contexto pode-se afirmar a importância de uma assistência integral à saúde da mulher em todo o processo gravídico-puerperal. O enfermeiro tem papel fundamental, pois possui conhecimento para oferecer informações necessárias em relação ao puerpério, suas transformações e demandas, com a finalidade de favorecer uma experiência materna de retorno à sexualidade efetivamente saudável e de bem-estar. 
Este estudo apresentou algumas limitações por tratar-se de um tema que envolve intimidade sexual, logo, muitas puérperas quando convidadas, se recusaram a participar. Desse modo, outras pesquisas a respeito da sexualidade da mulher no puerpério mostram-se imperiosas no sentido de conhecer e propiciar um melhor aprofundamento sobre a temática.

\section{Referências}

1. Brasil, Ministério da Saúde, Secretaria de Atenção à Saúde, Departamento de Atenção Básica. Saúde sexual e saúde reprodutiva. Brasília (DF): Ministério da Saúde; 2013.

2. Souza ER. Violências e vulnerabilidades em mulheres identificadas como vítimas de tráfico para fins sexuais [tese]. Rio de Janeiro: Instituto Fernandes Figueira; 2015. 142 p.

3. Bia FMM. Sexualidade pós-parto: a outra face da maternidade. Nursing (Ed Portuguesa). 2010 [acesso em 2016 mar 20];22(260):8-18. Disponível em: http://webcache.googleusercontent.com/search?q=cache:http://www.forumenfermagem.org/dossiertecnico/revistas/nursing/item/3573-sexualidade-pos-parto-a-outra-face-da-maternidade\#.XDK1ZS5Kg3w

4. Zugaib MZ. Obstetrícia. 3ª ed. Barueri: Manole; 2016. 450 p.

5. Montenegro CAB, Rezende Filho J. Obstetrícia Fundamental. 13aㅗ ed. Rio de Janeiro: Guanabara Koogan; 2017.

6. Oliveira ACM, Lopes CS, Melo MO, Jeneral RBR. Sentimentos vivenciados pelas mulheres no retorno à vida sexual após o parto. Rev Fac Ciênc Méd Sorocaba [Internet]. 2014 [acesso em 2016 abr 15];16(4):1747. Disponível em: http://revistas.pucsp.br/index.php/RFCMS/article/view/17651/pdf

7. Souza BMS, Souza SF, Rodrigues RTS. O puerpério e a mulher contemporânea: uma investigação sobre a vivência e os impactos da perda da autonomia. Rev SBPH [Internet]. 2013 [acesso em 2016 maio 10];16(1):166-84. Disponível em: http://pepsic.bvsalud.org/pdf/rsbph/v16n1/v16n1a10.pdf

8. Pereira MC, Gradim CVC. Consulta puerperal: a visão do enfermeiro e da puérpera. Ciênc Cuid Saúde [Internet]. 2014 jan-mar [acesso em 2016 abr 15];13(1):35-42. Disponível em: http:/ojs.uem.br/ojs/index.php/CiencCuidSaude/article/viewFile/19572/pdf_110 doi: 10.4025/cienccuidsaude.v13i1.19572

9. Ribeiro SG. Qualidade de vida relacionada à saúde em mulheres no puerpério imediato: uma análise a partir de diferentes tipos de parto [tese]. Fortaleza: Universidade Federal do Ceará, Faculdade de Farmácia, Odontologia e Enfermagem; 2016. 113p. 
10. Martins EL, Vargens OMC. Percepções de mulheres a respeito da sexualidade durante a amamentação: uma revisão integrativa. Rev Enferm UERJ [Internet]. 2014 [acesso em $2017 \mathrm{dez}$ 10];22(2):271-7. Disponível em: http://www.epublicacoes.uerj.br/index.php/enfermagemuerj/article/view/13670

11. Bardin L. Análise de Conteúdo. São Paulo: Edições 70; 2011. 229p.

12. Enderle CF, Kerber NPC, Lunardi VL, Nobre CMG, Mattos C, Rodrigues EF. Condicionantes e/ou determinantes do retorno à atividade sexual no puerpério. Rev Latinoam Enferm [Internet]. 2013 maiojun [acesso em 2017 dez 15];21(3):1-7. Disponível em: http://www.revistas.usp.br/rlae/article/view/75978/79522

13. Silva BCA, Amorim D, Nunes EC, Latorre GFS. Disfunção sexual feminina e parto normal: uma revisão integrativa da literatura. Rev Bras Ciên Saúde [Internet]. 2017 [acesso em 2018 fev 20];21(4)363-8. Disponível em: http://periodicos.ufpb.br/ojs2/index.php/rbcs/article/view/363-368

14. Teixeira RA, Oselame GB, Dutra DA, Oliveira EM, Neves EB. Consulta de pré-natal de enfermagem: cuidado além dos aspectos fisiológicos. Rev Univ Vale Rio Verde [Internet]. 2015 [acesso em 2016 mar 27];13(2):508-20. Disponível em: http://periodicos.unincor.br/index.php/revistaunincor/article/view/2346 doi: 10.5892/ruvrd.v13i2.2346

15. Schlagintweit HE, Bailey K, Rosen NO. A new baby in the bedroom: frequency and severity of postpartum sexual concerns and their associations with relationship satisfaction in new parent couples. J Sex Med [acesso em 2017 nov 20];13(10):1455-65. Disponível em: https://www.sciencedirect.com/science/article/pii/S174360951630371X doi: 10.1016/j.jsxm.2016.08.006

16. Salim NR, Araújo NM, Gualda DMR. Corpo e sexualidade: a experiência de um grupo de puérperas. Rev Latinoam Enferm [Internet]. 2010 jun-ago [acesso em 2017 dez 15];18(4):732-9. Disponível em: http://www.scielo.br/pdf/rlae/v18n4/pt_11.pdf doi: 10.1590/S0104-11692010000400011

17. Holanda JBL, Abuchaim ESV, Coca KP, Abrão ACFV. Disfunção sexual e fatores associados relatados no período pós-parto. Acta Paul Enferm [Internet]. 2014 [acesso em 2018 jan 15];27(6):573-8. Disponível em: http:/www.scielo.br/pdf/ape/v27n6/1982-0194-ape-027-006-0573.pdf doi: http://dx.doi.org/10.1590/1982-0194201400093

\section{Autor correspondente}

Mônica Cecília Pimentel de Melo

E-mail: monquinamelo@gmail.com

Endereço: Av. José de Sá Maniçoba S/N, bairro Centro, Petrolina - PE, Brasil. UNIVASF/Colegiado de Enfermagem.

CEP: $56.304-917$ 


\section{Contribuições de Autoria}

\section{1 - Larissa Karla Rocha Siqueira}

Concepção e planejamento do projeto de pesquisa, obtenção e análise e interpretação dos dados e redação.

2 - Mônica Cecília Pimentel de Melo

Revisão crítica, ajustes e correções.

3 - Ramon José Leal de Morais

Contribuições: revisão crítica, ajustes e correções.

\section{Como citar este artigo}

Siqueira LKR, Melo MCP, Morais RJL. Pós-parto e sexualidade: perspectivas e ajustes maternos. Rev. Enferm. UFSM. 2019 [Acesso em: 2019 jun 15];vol 9 ex:1-18. DOI:https://doi.org/10.5902/2179769233495 